mgr Patryk Suchodolski

Książnica Podlaska im. Łukasza Górnickiego

Dział Naukowy

patryk.suchodolski@ksiaznicapodlaska.pl

\title{
DIGITALIZACJA W KSIĄŻNICY PODLASKIEJ IM. ŁUKASZA GÓRNICKIEGO
}

\author{
Digitalization in Książnica Podlaska
}

\begin{abstract}
Abstrakt
W niniejszym artykule autor przedstawia działania podejmowane przez Książnicę Podlaską im. Łukasza Górnickiego w zakresie digitalizacji posiadanych materiałów - od książek, przez prasę i fotografię, po taśmy audio i nagrania audiowizualne. Pierwsze inicjatywy związane z cyfryzacją kolekcji wiążą się z udziałem w przedsięwzięciu utworzenia Podlaskiej Biblioteki Cyfrowej. W kolejnych latach Książnica Podlaska przystępowała do kolejnych projektów mających na celu dalszą budowę kompetencji cyfrowych, w tym digitalizacji oraz udostępniania najcenniejszych woluminów za pośrednictwem Internetu, na platformie Podlaskiej Biblioteki Cyfrowej. W rezultacie tych działań Książnica Podlaska nawiązała współpracę z szeregiem regionalnych instytucji kultury, zarazem podejmując inicjatywy związane z rozwojem współpracy transgranicznej.
\end{abstract}

Słowa kluczowe: Książnica Podlaska, digitalizacja, kompetencje cyfrowe, współpraca transgraniczna.

\begin{abstract}
In this article, the author depicts actions undertaken by Książnica Podlaska in the area of digitalization of its collections - from books, through press and photos, to audio tapes and audiovisual records. The first initiatives of digitalization are connected to participation in creation of the Podlaska Digital Library. In following years, Książnica Podlaska participated in other projects meant to further develop digital competences, including digitalization and publication of the most valuable volumes via the internet, on the platform of the Podlaska Digital Library. As a result of these projects,
\end{abstract}


Książnica Podlaska began cooperation with multiple regional institutions of culture and also took part in initiatives related to the development of cross-border cooperation.

Keywords: Książnica Podlaska, digitalization, digital competences, cross-border cooperation.

\section{Rozwój kompetencji digitalizacyjnych}

W 2004 r. Książnica Podlaska znalazła się w gronie założycieli Konsorcjum Bibliotek Naukowych Miasta Białegostoku, oprócz Biblioteki Uniwersyteckiej im. Jerzego Giedroycia, Archidiecezjalnego Wyższego Seminarium Duchownego, Politechniki Białostockiej, Uniwersytetu Medycznego i Wydziału Instrumentalno-Pedagogicznego Uniwersytetu Muzycznego Fryderyka Chopina. Głównym celem zrzeszenia było utworzenie regionalnej biblioteki cyfrowej oraz organizacja zaplecza niezbędnego do jej funkcjonowania, w tym pracowni digitalizacji. Oficjalne otwarcie Podlaskiej Biblioteki Cyfrowej (PBC) miało miejsce 11 grudnia 2006 r. Ze względu na kwestie formalne Książnica Podlaska do realizacji projektu dołączyła 15 marca 2007 r. Od tego momentu de facto możemy mówić o początku digitalizacji jej zbiorów ${ }^{1}$.

Były to trudne czasy, brak dedykowanej komórki organizacyjnej wymusił prowadzenie prac własnymi siłami Działów Informacyjno-Bibliograficznego oraz Instrukcyjno-Metodycznego. Kolejny problem stanowiły niedobory sprzętowe. Ten pierwszy etap cyfryzacji zasobu trwał do $2011 \mathrm{r}$. Wówczas zeskanowano i zamieszczono w Podlaskiej Bibliotece Cyfrowej 2056 obiektów, co przełożyło się na 19821 skanów publikacji uznanych za najcenniejsze, najciekawsze spośród druków związanych z regionem książek, czasopism oraz broszur ulotnych. Pośród nich znalazły się publikacje z supraskiej oficyny oo. bazylianów, urzędowe pisma białostockie z przełomu XVIII i XIX w. z drukarni Jana Kantera i Jana Appelbauma,

1 H. Brzezińska-Stec, W. Wróbel: Jubileusz dziesięciolecia Podlaskiej Biblioteki Cyfrowej 2006-2016. Białystok 2016, s. 3-5. 
wybrane dzieła Zygmunta Glogera², Łukasza Górnickiego ${ }^{3}$, dziewiętnastowieczne materiały rosyjskojęzyczne na temat Białegostoku, kolekcja czasopism z okresu dwudziestolecia międzywojennego (w tym wydawnictwa regionalne, gazetki szkolne, dzienniki urzędowe) $)^{4}$.

W 2011 r. wykonano kolejny ważny krok w budowie kompetencji cyfrowych poprzez rozpoczęcie projektu Elektroniczna Książnica Podlaska realizowanego w ramach programu Kultura+. Było to przedsięwzięcie dwuetapowe, zakończone w 2013 r. Jednym z jego celów stało się utworzenie wyspecjalizowanej, dobrze wyposażonej Pracowni Digitalizacji Zbiorów spełniającej wymogi dobrych praktyk digitalizacji dla obiektów bibliotecznych. Na jej siedzibę wybrano Filię nr 9 Książnicy przy ul. Gajowej w Białymstoku. W ramach pierwszego etapu projektu zakupiono skaner kołyskowy, skanery płaskie, cyfrowy aparat fotograficzny, stół do fotografii, kamerę cyfrową wraz z akcesoriami, zestawy komputerowe, laptopy, dyski przenośne oraz oprogramowanie niezbędne do skanowania, obróbki i konwersji otrzymanych plików. Dodatkowymi nabytkami były: serwer przeznaczony do tworzenia repozytorium cyfrowego, dyski przenośne, a także software przeznaczony do prowadzenia biblioteki cyfrowej.

W ramach projektu kontynuowano skanowanie regionaliów, a także starodruków przeznaczonych do zamieszczenia w Podlaskiej Bibliotece Cyfrowej. Wówczas zdigitalizowano materiały wchodzące w skład kolekcji „Z biblioteki Elizy Orzeszkowej”, zaliczające się głównie do literatury pięknej, autorstwa m.in. właścicielki tej kolekcji, również: Józefa Ignacego Kraszewskiego i Heleny Pajzderskiej (Hajoty) ${ }^{5}$, biblioteki Antoniego oraz Jakuba Wagów, pióra m.in. Teofila Lenartowicza, Łukasza Górnickiego

2 Wówczas na PBC udostępnione zostały: Białowieża. Warszawa 1907; Czy lud polski jeszcze śpiewa? Warszawa 1905; Dawna Ziemia Łomżyńska. Warszawa 1876; Dolinami rzek: opis podróży wzdłuż Niemna, Wisty, Bugu i Biebrzy. Warszawa 1903; Popas w Sławopolu. Warszawa 1891.

3 Dworzanin polski. Kraków 1639; Dzieje w Koronie Polskiej... Warszawa 1754; O elekcyi, prawie i obyczajach polskich: rozmowa Polaka $z$ Włochem. Sanok 1855.

4 Książnica Podlaska im. Łukasza Górnickiego w Białymstoku. Przewodnik. Red. E. Kołomecka. Białystok 2010, s. 49-50. Przewodnik wspomina o zdigitalizowaniu w tym okresie również pism Krzysztofa Kluka. Nie precyzuje jednak, o jakie wydawnictwa chodzi, faktu ich zeskanowania nie udało się potwierdzić ani w Dziale Digitalizacji, ani Dziale Zbiorów Specjalnych Książnicy Podlaskiej.

5 Książki z biblioteki Elizy Orzeszkowej zdigitalizowane. Tryb dostępu: http://www.ksiaznicapodlaska.pl/site/aktualnosci/ [24 października 2018]. 
czy Adama Mickiewicza ${ }^{6}$. Oprócz nich w PBC znalazły się czasopisma Podlaskiego Regionu NSZZ „Solidarność”: „Wiadomości Bieżące” z lat 1981 oraz 1989, „Biuletyn Informacyjny NSZZ »Solidarność« Region Podlaski” z lat 1980-1989, 1990, 1993-1999, 2000-20067.

Oprócz tego podjęto działania mające na celu pozyskanie zdigitalizowanych materiałów dotyczących Podlasia, rozproszonych w różnych instytucjach: Bibliotece Narodowej, Bibliotece Uniwersytetu Warszawskiego i Poznańskim Towarzystwie Przyjaciół Nauk. Zamówione skany, po poddaniu obróbce w Pracowni Digitalizacji Zbiorów, zostały opublikowane w PBC. Pracownia służyła pomocą również innym placówkom, z jej możliwości korzystały biblioteki publiczne województwa podlaskiego oraz Archiwum Państwowe w Białymstoku ${ }^{8}$.

Kolejne zmiany nastały wraz z rokiem 2016, kiedy to utworzono osobny Dział Digitalizacji, który ulokowano w nowej siedzibie Książnicy przy ul. Marii Skłodowskiej-Curie. Rozpoczęto również kolejny projekt, rozpisany na dwa lata Skarbiec dziedzictwa kulturowego, w ramach którego dział został wyposażony w nowy sprzęt, w tym skaner planetarny oraz serwer przeznaczony do przechowywania kopii wzorcowych skanów.

Digitalizację prowadzi także Dział Zbiorów Specjalnych Książnicy Podlaskiej, który w styczniu 2017 r. rozpoczął konwersję taśm magnetofonowych na formaty cyfrowe. Obecnie zajmuje się Książkami Mówionymi, wydawanymi przez Polski Związek Niewidomych od początku lat sześćdziesiątych ubiegłego wieku do 2010 r. W zbiorach działu znajduje się około czterech tysięcy pozycji wydanych w ramach tej serii, część z nich, niestety, uległa już zniszczeniu. Większość kaset poddawanych cyfryzacji zawiera

6 Co czytali Wagowie? Odpowiedź na pytanie przynosi zdigitalizowany fragment biblioteki z Grabowa zachowany w zbiorach Ksiązinicy Podlaskiej. Tryb dostępu: http://www. ksiaznicapodlaska.pl/site/aktualnosci/ [25 października 2018].

7 Lekcja najnowszej historii w Podlaskiej Bibliotece Cyfrowej - czasopisma regionalnej „Solidarności” z lat 80-tych udostępnione w sieci Internet. Tryb dostępu: http://www. ksiaznicapodlaska.pl/site/aktualnosci/ [25 października 2018].

8 Program Wieloletni Kultura+. Priorytet Digitalizacja. Projekt „Elektroniczna Książnica Podlaska - Etap I". Tryb dostępu: http://www.ksiaznicapodlaska.pl/site/projekty/ekp/ [1 października 2018]. Program Wieloletni Kultura+. Priorytet Digitalizacja. Projekt „Elektroniczna Książnica Podlaska - Etap II”, Program Wieloletni Kultura+. Priorytet Digitalizacja. Projekt „Elektroniczna Książnica Podlaska - Etap I”. Tryb dostępu: http://www.ksiaznicapodlaska.pl/site/projekty/ekp/ [1 października 2018]. Digitalizowane publikacje. Tryb dostępu: http://www.ksiaznicapodlaska.pl/site/projekty/ekp/ /dokumenty.html [1 października 2018]. Pracownia digitalizacji. Tryb dostępu: http:// www.ksiaznicapodlaska.pl/site/projekty/ekp/pracownia.html [1 października 2018]. 
literaturę piękną, zwłaszcza tytuły dotychczas niewydane $\mathrm{w}$ formie audiobooka. Wśród nich znajdują się dzieła klasyków polskiej literatury, m.in.: Józefa Ignacego Kraszewskiego, Henryka Sienkiewicza, Marii Rodziewiczówny, Jana Dobraczyńskiego, Tadeusza Dołęgi-Mostowicza, czytane przez uznanych aktorów, takich jak: Anna Nehrebecka, Zdzisław Wardejn, Anna Romantowska, Leszek Teleszyński, Krzysztof Kołbasiuk oraz lektorów: Mirosława Uttę, Rocha Siemianowskiego czy Jacka Kissa.

W kontekście tematu zabezpieczenia zbiorów warto wspomnieć o zadaniach dofinansowanych ze środków Ministerstwa Kultury i Dziedzictwa Narodowego poświęconych konserwacji najstarszych i najbardziej wartościowych obiektów znajdujących się w kolekcji Książnicy Podlaskiej, które następnie były digitalizowane oraz zamieszczane w PBC. Pierwszą taką inicjatywę podjęto w 2009 r. Renowacji zostało poddanych wtedy pięć druków ulotnych władz pruskich pochodzących z 1801 r., z wspominanych już oficyn drukarskich Jana Kantera i Jana Appelbauma ${ }^{9}$. Następnie w latach 2012-2014 przystąpiono do programu Dziedzictwo kulturowe - wspieranie działań muzealnych, w ramach którego podjęto się zabezpieczenia siedmiu starodruków oraz jednego rękopisu ${ }^{10}$. Ostatnim takim przedsięwzięciem była konserwacja dziesięciu starodruków przeprowadzona w trakcie wspominanego już projektu Skarbiec dziedzictwa kulturowego, dofinansowanego z Europejskiego Funduszu Rozwoju Regionalnego. W jego ramach dodatkowo przewidziano utworzenie specjalistycznego magazynu w Dziale Zbiorów Specjalnych, służącego bezpiecznemu przechowywaniu najcenniejszych woluminów ${ }^{11}$.

9 Konserwacja 5 woluminów białostockich druków ulotnych wydanych w 1801 r. Tryb dostępu: http://www.ksiaznicapodlaska.pl/site/projekty/konserwacja/ [2 października 2018].

10 W 2012 r. zdigitalizowano: Ritualis, altera pars de cearemoniis ecclesiasticis. De Benedictionibus, Reguale Generale. Kraków 1730; Leitourgikon Si est'Służebnik. Wilno - Supraśl 1692. W 2013 r.: Generalna Stanów Wielkiego Księstwa Litewskiego Konfederacyja zaczęta w Wilnie Roku 1764 dnia 16 miesiąca kwietnia... 1764; Zlatoust. Supraśl 1797; Irmologion powstały między 1650 a 1770 r. (rkps). W 2014 r.: F. Paprocki: Woyny znacznieysze przed narodzeniem i po narodzeniu Chrystusa Pana aż do ostatniego pokoju paryskiego i hubertsburskiego roku 1763... Wilno 1763; A. Zamoyski: Zbiór praw sadowych na mocy konstytucyi roku 1776 [...] na Seym 1778 podany. Warszawa 1778; „Gazeta Warszawska" (niepełne roczniki 1774 i 1775).

11 Renowacji zostały poddane następujące pozycje: Biblia, to iest Księgi Starego y Nowego Testamentu według Lacińskiego przekładu starego, w kościele powszechnym przyiętego, na polski ięzyk z nowu z pilnościa przełożone, z wykładem katholickim trudniejszych mieysc, do obrony wiary świetey powszechney. Przedtem przez D. Iakuha Wuyka 


\section{Współpraca}

Oprócz działań podejmowanych we własnym zakresie Książnica Podlaska współpracuje z innymi instytucjami kultury, głównie regionalnymi, choć nie tylko. W latach 2016-2017 jako partner Centrum im. Ludwika Zamenhoffa (CLZ) brała udział w realizacji projektu eMediateka CLZ dotowanego z programu Kultura Cyfrowa Ministerstwa Kultury i Dziedzictwa Narodowego. Jego celem było zwiększenie dostępności materiałów zgromadzonych $\mathrm{w}$ repozytorium CLZ poprzez zamieszczenie ich online. W rezultacie na stronach e-Mediateki, Ośrodka Karta i Podlaskiej Biblioteki Cyfrowej znalazło się 80 relacji ustnych dotyczących przeszłości Białegostoku oraz Podlasia (łącznie około 108 godzin nagrań), a także 2200 obiektów ikonograficznych ${ }^{12}$. Współpraca jest kontynuowana w ramach kolejnego projektu zaplanowanego na lata 2018-2019.

Kolejną inicjatywą dofinansowywaną z programu Kultura Cyfrowa był projekt Podlaskie Zbiory Cyfrowe realizowany w kooperacji z Wojewódzkim Ośrodkiem Animacji Kultury w Białymstoku (WOAK) w latach 2017-2018. W rezultacie został uruchomiony portal, na którym znalazły

$z$ Wagrowca wydane w Krakowie 1599 teraz wydrukowane. Wrocław 1740; A. Bakanowski: Quaestiones theologicale canonico-morales, ex materiis de septem Sacramentis ss. Canonum, conciliorum, et ss. Patrum authoritate firmate, per casus factos, non fictos explanantae. Wilno 1732; J. H. Böhmer: Ivsti Hennig Boehmeri. Introductio in ius digestorum sensum pariter acusum singularum materiarum succincte exhibens, accesserunt tituli de uerborum significatione et regulis iuris ad seriem materiarum ordine alphabetico congesti cun duplici indice. Haale 1723; A. Poniński: Opera Heroica Illustrissimi Domini Antonij Łodzia a Ponin Poninski, Palatini Posnaniensis Equitis Ordinis Aquilae Albae, olim sub nomine Equitis Poloni sparsim edita, nunc vero plurimum aucta, cura, studio et impensis Joannis Maximiliani Krolikiewicz Sacrae Regiae Maiestatis Secretarii, impressa. Warszawa 1739; Konstytucye Seymu extra ordynaryinego Warszawskiego pod węzłem Generalney Konfederacyi Oboyga Narodow trwaiącego Roku 1773 dnia 19 Kwietnia zaczętego, a z Limity y sześciu prorogacyi w roku 1775 przy utwierdzeniu dziel generalnych Konfederacyi y rozwiązaniu onychże skończonego za zgoda zgromadzonych y skonfederowanych Stanów uchwalone (t. I-III, współoprawne). Warszawa 1775; A. Miastkowski: Deus in essentia Unus, in personis Trinus, sex disputationibus theologice propugnatus. Praga 1723; R. Wojniłowicz: Kazania Świąteczne na cały rok. Nieśwież 1756; Biblia, to jest Ksiegi Starego y Nowego Testamentu. Gdańsk 1632; H. de Saint-Cher: Domini Hvgonis cardinalis Postilla super Epistolas Pauli [...], item super Actus apostolorum, super epistolas Canonicas, item super Apocalypsim; Sexta pars. Paryż 1538; Dziennik Seymu Głównego Ordynaryinego Warszwskiego pod związkiem Konfederacyi Oboyga Narodow roku 1789 z zlecenia Stanow: sessya CLXXXII-CXCVII. 1789.

12 „Mediateka” - multimedialne archiwum historii mówionej miasta i regionu. Tryb dostępu: http://www.ksiaznicapodlaska.pl/site/aktualnosci/ [25 października 2018]. 
się zdigitalizowane materiały dokumentujące przeszło sześćdziesięcioletnią działalność WOAK-u, takie jak: taśmy audio, filmowe, zdjęcia, księgi pamiątkowe, kroniki, plakaty, a także katalogi zbiorów Książnicy Podlaskiej - alfabetyczne katalogi kartkowe książek, czasopism, płyt, również według symboli wydawniczych. Łącznie cyfryzacji poddano ponad 308 godzin nagrań audio i wideo, ponad 3 tys. obiektów piśmienniczych i ikonograficznych oraz około 120 tys. kart katalogowych ${ }^{13}$.

W 2016 r. Książnica Podlaska wspólnie z Obwodową Biblioteką Naukową im. Jana Karskiego w Grodnie złożyła wniosek o dofinansowanie projektu: Współpraca instytucji kultury Białostocczyzny i Grodzieńszczyzny $w$ zakresie rozwoju zasobów cyfrowych i udostępniania danych jako czynnik wzrostu czytelnictwa $i$ wzmocnienia więzi literacko-kulturowych na obszarze transgranicznym w ramach Programu Współpracy Transgranicznej Polska - Białoruś - Ukraina 2014-2020. Jego celem jest zwiększenie dostępu do regionaliów znajdujących się w zbiorach obu instytucji, które, ze względu na przebieg współczesnych granic międzynarodowych, pozostają rozproszone. Planuje się to osiągnąć za pomocą digitalizacji oraz zamieszczenia na specjalnie $\mathrm{w}$ tym celu utworzonej stronie internetowej określonych pozycji dotyczących dwóch blisko ze sobą związanych obszarów, przez długi czas funkcjonujących w obrębie jednego państwa. Wiąże się to $\mathrm{z}$ dalszym rozwijaniem kompetencji obu bibliotek w zakresie cyfryzacji, $\mathrm{w}$ tym również $\mathrm{z}$ rozbudową infrastruktury, niezbędnej w realizacji tego przedsięwzięcia. Dodatkowo w celach popularyzacyjnych przewiduje się m.in. wydanie pięciu publikacji zawierających najciekawsze i najbardziej wartościowe pozycje skierowane do dorosłych i do dzieci oraz organizację dwóch konferencji popularnonaukowych.

\section{Podsumowanie}

Digitalizacja w Książnicy Podlaskiej trwa już od przeszło dekady. W tym czasie zeskanowano i udostępniono niemal 30 tys. obiektów, w tym około 1,2 tys. książek, 23 tys. czasopism, 120 kaset VHS oraz 700 nagrań audio. Do tego należy doliczyć ponad 3,2 tys. obiektów zapisanych w formatach cyfrowych $\mathrm{w}$ ramach kooperacji z innymi instytucjami kultury. Stopniowa budowa odpowiedniego zaplecza oraz kadry pracowniczej odbywa się dzięki umiejętnemu wykorzystaniu możliwości oferowanych przez

13 Podlaskie zbiory cyfrowe. Tryb dostępu: http://www.ksiaznicapodlaska.pl/site/aktualnosci/ [27 października 2018]. 
rozmaite programy finansowane przez Unię Europejską, które pozwoliły również na renowację najcenniejszych, a zarazem najbardziej sfatygowanych druków znajdujących się w kolekcji Książnicy Podlaskiej oraz zapewnienie im właściwych warunków przechowywania. Istotną rolę odgrywa tutaj współpraca $\mathrm{z}$ innymi instytucjami kultury z regionu, jak również z zagranicy, która będzie kontynuowana w przyszłości.

\section{Bibliografia}

1. Co czytali Wagowie? Odpowiedź na pytanie przynosi zdigitalizowany fragment biblioteki $z$ Grabowa zachowany w zbiorach Książnicy Podlaskiej. Tryb dostępu: http://www.ksiaznicapodlaska.pl/site/aktualnosci/ [25 października 2018].

2. Digitalizowane publikacje. Tryb dostępu: http://www.ksiaznicapodlaska.pl/ site/projekty/ekp/dokumenty.html [1 października 2018].

3. Konserwacja 5 woluminów białostockich druków ulotnych wydanych w 1801 r. Tryb dostępu: http://www.ksiaznicapodlaska.pl/site/projekty/konserwacja/ [2 października 2018].

4. Książki z biblioteki Elizy Orzeszkowej zdigitalizowane. Tryb dostępu: http:// www.ksiaznicapodlaska.pl/site/aktualnosci/ [24 października 2018].

5. Ksiąznica Podlaska im. Łukasza Górnickiego w Białymstoku. Przewodnik. Red. E. Kołomecka. Białystok 2010.

6. Ksią̇nica Podlaska im. Łukasza Górnickiego. Informator. Red. E. Kołomecka. Białystok 2010.

7. Lekcja najnowszej historii w Podlaskiej Bibliotece Cyfrowej-czasopisma regionalnej „Solidarności” $z$ lat 80-tych udostępnione w sieci Internet. Tryb dostępu: http://www.ksiaznicapodlaska.pl/site/aktualnosci/ [25 października 2018].

8. „Mediateka” - multimedialne archiwum historii mówionej miasta i regionu. Tryb dostępu: http://www.ksiaznicapodlaska.pl/site/aktualnosci/ [25 października 2018].

9. Podlaskie zbiory cyfrowe. Tryb dostępu: http://www.ksiaznicapodlaska.pl/site/ aktualnosci/ [27 października 2018].

10. Pracownia digitalizacji. Tryb dostępu: http://www.ksiaznicapodlaska.pl/site/ projekty/ekp/pracownia.html [1 października 2018].

11. Program Wieloletni Kultura +. Priorytet Digitalizacja. Projekt „Elektroniczna Książnica Podlaska - Etap I". Tryb dostępu: http://www.ksiaznicapodlaska.pl/ /site/projekty/ekp/ [1 października 2018].

12. Program Wieloletni Kultura+. Priorytet Digitalizacja. Projekt „Elektroniczna Ksiażnica Podlaska - Etap II", Program Wieloletni Kultura+. Priorytet Digitalizacja. Projekt „Elektroniczna Ksiażnica Podlaska - Etap I”. Tryb dostępu: http://www.ksiaznicapodlaska.pl/site/projekty/ekp/ [1 października 2018]. 